\title{
Wave of unity
}

\author{
The ocean connects all corners of the Earth. It supports life, and we need to better understand and support it to
} ensure a prosperous future.

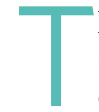
he ocean holds a fascination for many - the great unknown, the freedom of the seas - but for many more, it is their food source, part of their everyday life and essential for existence. Yet funding to study the ocean, at an average of $1.7 \%$ of national research budgets ${ }^{1}$, is low. To address this, 2021-2030 has been designated the United Nations (UN) Decade of Ocean Science for Sustainable Development (www. oceandecade.org). Declaring the decade in December 2017, the UN set the agenda for international cooperation, mobilizing researchers, policy makers, businesses and civil society to work together to stop the decline in ocean health and ensure a sustainable resource for years to come.

With most of the ocean being a global common, it is a societal responsibility to work together to ensure its protection. Climate change is known to be affecting the ocean in a number of ways, and the ocean has begun to receive more attention in climate negotiations - a study in 2017 found $70 \%$ of the 161 national determined contributions to the Paris Agreement included marine issues ${ }^{2}$.

Increased temperature is the cause of coral bleaching, a visual and well-reported effect of climate change, and more heat is being added and stored in the ocean each year. Recent work shows that, regarding the top 2,000 m, the year 2020 showed the highest rate of ocean heat content increase on record ${ }^{3}$, and at the regional scale for the upper $700 \mathrm{~m}$ (ref. ${ }^{4}$ ), larger sections of the ocean are showing statistically significant warming trends and less areas are showing cooling trends. As well as this general increase in ocean heat, marine heatwaves are occurring more frequently and events can persist for long periods (for example, the North Pacific blob ${ }^{5}$ ). Yet our ability to predict these events, and therefore better manage marine ecosystems and food resources, is still quite variable, ranging from days to years in advance depending on the region and drivers of specific events ${ }^{6}$.

Alongside increased heat, there are associated physical changes underway

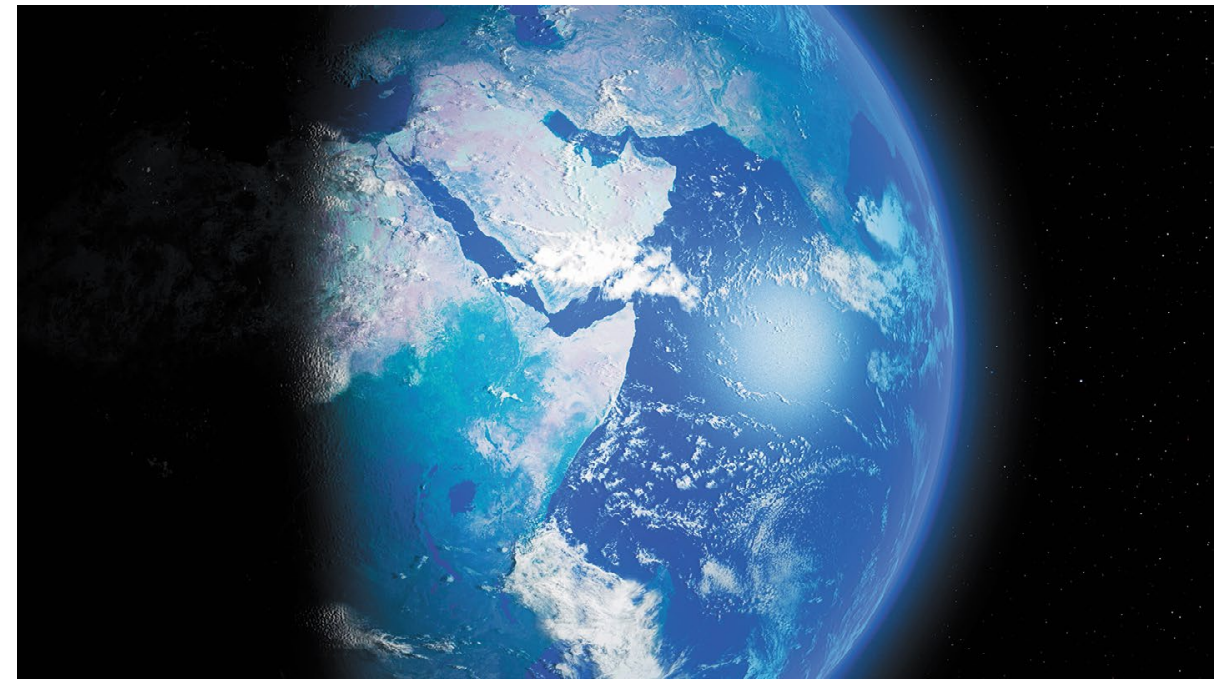

Credit: Science Photo Library / Alamy Stock Photo

that will impact ocean ecosystem health. For example, stratification has increased, limiting vertical exchange (for example, of nutrients) through the water column by $\sim 5 \%$ since 1960 (ref. ${ }^{7}$ ). Deoxygenation (where warmer water holds less oxygen and, coupled with changes in stratification and circulation, changes the amount of oxygen entering the deep ocean) has potential wide-ranging effects on fisheries and ecosystems ${ }^{8}$.

These changes put pressure on species for which relocation (poleward or within water column) is necessary for survival. Fisheries in least-developed countries are most vulnerable to these climate change effects ${ }^{9}$ with less adaptive capacity; however, the effects are ubiquitous, as shown in a case study of New England and Mid-Atlantic USA fishing communities ${ }^{10}$.

Ocean governance relies on the cooperation of nations. Part of the push for great ocean commitment is coming from the High Level Panel for a Sustainable Ocean Economy, established in 2018 and comprising of leaders from 14 nations, who are leveraging leading researchers around the world to advise them on the state of ocean science ${ }^{11}$. Raising awareness and prominence of ocean issues, as is the aspiration of this UN decade, will benefit us all by focusing attention to a crucial but understudied part of our planet.

Published online: 8 February 2021 https://doi.org/10.1038/s41558-021-00995-x

References

1. International Oceanographic Commission. Global Ocean Science Report 2020: Charting Capacity for Ocean Sustainability, Executive Summary (eds Isensee, K.) Report no. IOC/POL/2020/1 (United Nations Educational, Scientific and Cultural Organization, 2020); https://unesdoc.unesco.org/ark:/48223/pf0000375148

2. Gallo, N. D., Victor, D. G. \& Levin, L. A. Nat. Clim. Change 7, 833-838 (2017)

3. Cheng, L. J. et al. Adv. Atmos. Sci. https://doi.org/10.1007/s00376021-0447-x (2021)

4. Johnson, G. C. \& Lyman, J. M. Nat. Clim. Change 10, 757-761 (2020).

5. Di Lorenzo, E. \& Mantua, N. Nat. Clim. Change 6, 1042-1047 (2016).

6. Holbrook, N. J. et al. Nat. Rev. Earth Environ. 1, 482-493 (2020).

7. Li, G. et al. Nat. Clim. Change 10, 1116-1123 (2020).

8. Shepherd, J. G., Brewer, P. G., Oschlies, A. \& Watson, A. J. Phil. Trans. R. Soc. A 375, 20170240 (2017).

9. Blasiak, R. et al. PLoS ONE 12, e0179632 (2017).

10. Rogers, L. A. Nat. Clim. Change 9, 512-516 (2019).

11. Nature 588, 7-8 (2020). 